Article

\title{
Smart City: A Shareable Framework and Its Applications in China
}

\author{
Chengming Li, Xiaoli Liu, Zhaoxin Dai * and Zhanjie Zhao \\ Chinese Academy of Surveying and Mapping, Beijing 100830, China \\ * Correspondence: daizx@1reis.ac.cn
}

Received: 19 June 2019; Accepted: 8 August 2019; Published: 12 August 2019

\begin{abstract}
Smart City is a new concept that uses information and communication technology (ICT) to promote the smartification of urban construction, planning and services. Currently, a number of cities have conducted studies on smart cities, but they have mostly focused on analyzing the conceptual connotations or applications in specific domains and lack a shareable and integrated framework, which has led to significant barriers for individual smart projects. By analyzing the framework and applications of Smart City, this paper proposes a common, shareable and integrated conceptual framework. Then, based on this framework, it further proposes a unified portal platform that can balance multiple stakeholders, including the government, citizens and businesses, as well as for common, custom and other application modes. Finally, the implementation of Smart Weifang based on this platform is discussed. The applications indicate that this shareable platform can effectively eliminate the data and technological barriers between different smart city systems while also avoiding redundant financial investments. The investigation of this proposed framework and platform is highly significant for the unified construction of smart cities and the intensification of the hardware environment, thus representing a true achievement in the transition from 'information islands' to 'information sharing and interconnection' for urban informatization.
\end{abstract}

Keywords: Smart City; sharable framework; spatiotemporal data; cloud platform; smart Weifang

\section{Introduction}

The United Nations World Urbanization Prospects reports that more than half of the global population currently lives in cities, and this percentage can be expected to reach $66 \%$ by $2050[1,2]$. The accelerating rate of urbanization has been accompanied by numerous challenges for urban development, and a series of "urban diseases" have become increasingly prominent, such as resource shortages, environmental pollution, traffic congestion and security threats [3]. However, the continuous development of information and communication technology (ICT) has also led to improvements in the application of urban informatization, enabling information technology to become an effective means and tool for urban governance, eventually giving rise to the concept of the smart city.

The term 'smart city' appeared for the first time in the early 1990s, when in 1993, then US President Bill Clinton proposed the information superhighway program and emphasized the concepts of technology, innovation and globalization in the urbanization process $[4,5]$. Since 2008, with the launch of IBM's Smarter Planet project, the smart city has attracted substantial attention, and conceptual research on the smart city has undergone rapid growth and development [6]. Harrison et al. (2010) defined smart cities as intelligent cities with wide interconnections in infrastructure, the Internet, society and businesses [7]. Giffinger and Gudrun (2010) provided six major characteristics of a smart city: Smart economy, smart people, smart governance, smart mobility, smart environment and smart living [8]. As an alternative to the traditional city planning model, a common definition for a smart city is a new concept and mode to promote the intellectualization of urban planning, management 
and services by using ICT, such as the Internet of things (IoT), cloud computing and geospatial information [9-12]. Based on research on the smart city conceptual framework and characteristics, practical studies on smart cities have been conducted, such as the smart e-government "I-Japan Strategy" in Japan, the intelligent transportation study in Sweden, the smart grid projects in the US, and the smart community in Germany.

However, despite the large amount of research conducted by numerous countries and cities on the smart city and the substantial progress that they represent, they mostly focused on the analysis of the conceptual framework and applications in specific domains (e.g., smart transportation) and lack a common, shareable and integrated framework of understanding. A city is a giant complex system. To meet the ever-changing needs of its citizens, all systems within the city should communicate accurately with each other and share and utilize each other's resources in a timely and rapid manner [13]. Smart projects in specific domains usually have the characteristics of a resource monopoly and mutual independence, which leads to the following issues: (1) The inability to guarantee the consistency of public data and the spatial base for different smart projects in the same city; (2) the inability to achieve the sharing and integration of different smart systems or data in smart cities; (3) the inability to guarantee consistency across different smart project implementations due to different viewpoints of the project implementers or researchers; and (4) the inability to guarantee balance across various stakeholders (government, public administration and company).

The objectives of this paper are: (1) To explore and summarize the key elements or concept of a smart city through the literature analysis; (2) to propose a common, shareable and integrated conceptual framework for smart city; (3) to verify the effectiveness of the proposed smart city framework by using an application of the concept in China. Based on this framework, a unified portal platform that is suitable for multiple domains, including the government, citizens and businesses as well as for common, custom and other application modes, is then proposed. The research on this framework and platform has important implications for the unified construction of smart cities and the intensification of the hardware environment. It represents a true achievement in the transition from an "information island" to an "information sharing and interconnection" in urban informatization.

\section{Literature Review}

\subsection{Concepts of Smart Cities}

An understanding of the concepts of smart cities is of crucial significance in understanding its scope and content and guiding the development of its framework. For instance, the British Standards Institution (BSI)'s work on smart city measurement builds on the smart city framework, Publicly Available Specification (PAS) 181 standards [14] and International Standards Organization (ISO)'s work on a common framework for how city leaders across the globe can implement Smart City [15]. As a new model of urban development, the smart city has broad conceptual extensions. Although it has been studied by numerous researchers and institutions, various concepts have been addressed by stakeholders adopting several different perspectives [16-19]. There has been little research to perform an explicit classification of definitions of the smart city from different perspectives. Based on a comprehensive analysis of the conceptual connotations and applications of the smart city, this paper conducted and analyzed the definitions of the smart city considering four aspects: Software and hardware infrastructure, spatiotemporal data and analysis, cloud platform systems and applications.

Software and hardware infrastructure: Software and hardware infrastructure is a basic and key part for Smart City. With advanced monitoring systems and built-in smart sensors, data can be collected and evaluated in real-time, providing support for data mining and decision-making. For instance, in 2008, IBM describes a smart city as a city that can fully utilize the interconnections in physical infrastructure, IT infrastructure, social infrastructure and business infrastructure to produce collective intelligence; this definition emphasizes the connecting of the technical infrastructures of a city. From the point of importance of hardware infrastructure, such as sensors and network facilities in smart 
cities, Hall et al. (2000) proposed that smart cities are cities that monitor and integrate all of their critical infrastructure and make use of connections with networks and decision-making algorithms to optimize resources and monitor target security [19]. Schaffers et al. (2011) considered smart cities to be a model of urban development that makes use of ubiquitous networking and modern information technology to improve the city's competitiveness, achieve sustainable urban development and improve residents' quality of life [20].

Spatiotemporal data and analysis: With the development of advanced monitoring systems and smart sensors, a massive amount of data is generated from urban operations in various domains, including transportation, urban administration and businesses. Thus, spatiotemporal data with time and location characteristics have become important assets for smart cities, playing a crucial role in the construction and development of new smart cities [21,22]. Instrumentation enables the capture and integration of real-world data through operations; interconnection allows the data obtained from instrumentation to be integrated; and finally, intelligence means that data processing by using new insights that drive decisions and actions which can demonstrate a tangible added value [7]. Hashem et al. (2016) reported that the expansion of big data and analytics played an important role in the feasibility of smart city initiatives and pointed that the combination of the IoT and big data is an unexplored research area that has brought new and interesting challenges for achieving the goal of future smart cities [23]. By discussing and comparing different definitions of the smart city and big data, Nuaimi et al. (2015) pointed out that big data analytics is a huge potential to enhance smart city services, this due to that digitization has become an integral part of everyday life, data collection has resulted in the accumulation of huge amounts of data that can be used in various beneficial application domains, and effective analysis and utilization of big data is a key factor for success in the smart city domain $[24,25]$.

Cloud platform system: Building up a flexible and efficient platform between data sources and applications is the key to achieve the construction of a smart city. $\mathrm{Li}$ (2014) reported that the smart city is supported by a system that connecting data and users, the system includes spatiotemporal information, cloud computing and the IoT, which serves as a carrier for other information sharing, exchange and coordination services and providing intelligent application services [26]. Li et al. (2011) believed that smart cities will change the interaction between governments, businesses and the public by using a smart approach and involving new information technologies, with the IoT and cloud computing as cores, and this smart approach is actually an integrated system of multiple decision-making and service algorithms, which play a foundational and pre-emptive role in the construction of smart cities [27]. Javidroozi et al. (2014) proposed that for a city to be smart, it is necessary to integrate its city systems to deliver efficient services flexibly and in real-time [13]. The above definitions of smart city emphasize the importance of a smart and common information platform system in the construction and application of a smart city [28].

Application domains: The objective of a smart city is to form intelligent domains that are independent or less dependent on humans, and the combination and optimization of domains based on demand. Giffinger et al. (2007) defined a smart city as including a smart economy, smart people, smart governance, smart mobility, a smart environment and smart living [8]. Lazaroiu and Roscia (2012) were more didactic in their perspectives on the environment, energy and management and proposed that a smart city should include a smart economy, smart governance, a smart environment, smart energy and smart mobility [29]. The European Commission (2012) defined a smart city as a city with applications in energy efficiency, renewable energy and green urban transportation [30]. Washburn et al. (2009) believe that a smart city ensures smarter, better connected and more efficient city administration, education, healthcare, public safety, real estate, transportation and utilities [13].

\subsection{Applications for the Smart City and Shortcomings}

As the most creative urban form, the smart city has become the strategic choice for cities aiming to achieve development. At present, researchers are using new information technologies to conduct 
studies of practical applications based on a conceptual framework of the smart city, such as smart healthcare [31,32], smart transportation [33,34], smart tourism [35-37] and smart management [38]. However, most previous studies have focused on analysis and smart city construction in for single research field area. There also have a few smart projects that concentrate on various fields, such as Smart Matsushima New Town in Korea and the Smart Island in Singapore, but they still just take a city as the study object and perform the smart city construction in some specific fields, such as smart transport, living and environment, through the traction of the government. The conceptual framework and the top-level design that can be integrated and shared for all smart systems across the city are still lacking. Overall, the shortcomings of previous research are as follows (Figure 1): (1) Conceptual frameworks of the smart city still lack a common understanding and definitions reflect various aspects, (2) when facing different user demands (the government, the public, business, etc.) in the construction of the smart city, the construction of smart projects in different domains within the same city will not be uniform and may have, for example, inconsistencies in baseline data standards, data spatiotemporal benchmarks and public processing technology, as well as the widespread phenomenon of resource monopoly, causing serious obstacles for various smart projects due to poor shareability and integration. For a real smart city, it is necessary to integrate all systems and to achieve mutual communication and fusion between the systems, thereby sharing and utilizing each other's services in a timely, accurate and rapid manner $[13,14]$. To address these issues, this paper proposes a new common, shareable and integrated conceptual framework and platform for smart cities that can achieve the sharing and fusion of different smart projects in the city, as well as balance the demands of different stakeholders (the government, public and businesses) and different levels of users.
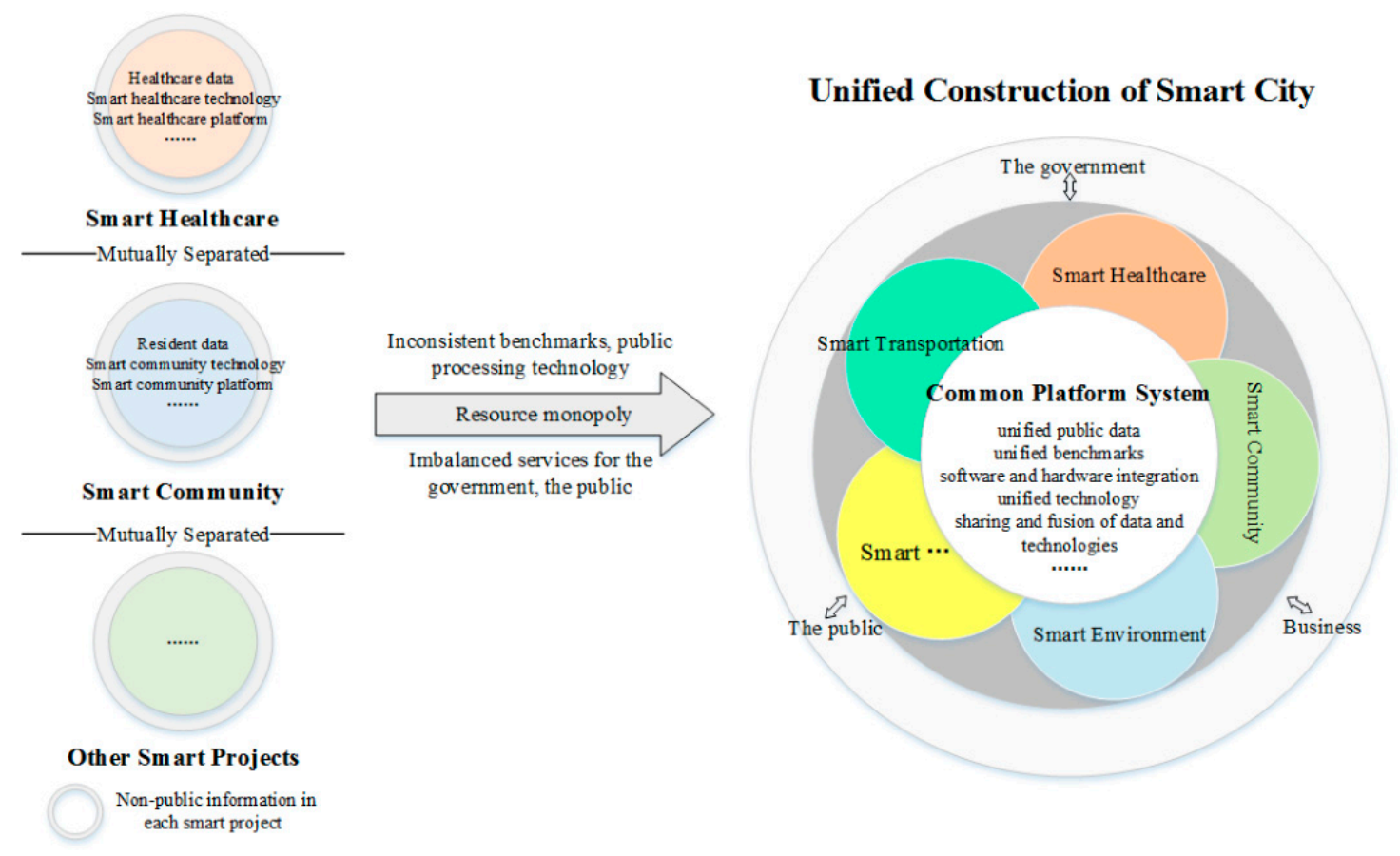

Figure 1. Schematic diagram of existing problems and strategies for smart cities.

\section{Results of Smart City Framework Understanding}

\subsection{Overall Framework}

A comprehensive analysis was conducted of the conceptual connotations and construction practices of smart cities. Although there were differences and distinctive characteristics in the understanding of connotations, framework construction and application domains, there were also commonalities in the system frameworks. The smart city is a system centered on information communication and geospatial information technologies, with an orientation towards a series of key technologies and applications in 
the construction, operation, service and management of urban informatization. The key technologies include big data, intelligent sensing, next-generation communication networks, cloud computing, virtual reality, artificial intelligence, spatiotemporal information and other new technologies [39]. The domain applications involve various aspects of government, civil and commercial services for urban land, planning, public security, environmental protection, transportation, energy, agriculture, hygiene, quality inspection, population, education, tourism and business, which are crucial technological pathways for the comprehensive and coordinated development of cities through integrated operations and information technology [25].

Based on the understanding of the smart city, and to realize the shareability of smart cities, the inconsistency of data, spatial geographic information and technology in smart projects must be dealt with. This paper integrates and re-organizes the basic key elements of Smart City, and proposed a common, shareable and integrated conceptual (systems) framework from the aspects of data, technology and processing to a multi-stakeholder application, as shown in Figure 2. It includes the sensing layer, network layer, computing and storage facility layer, public database layer, public information platform layer, applications layer and users layer, as well as the institutional security assurance system and policy standards assurance system.

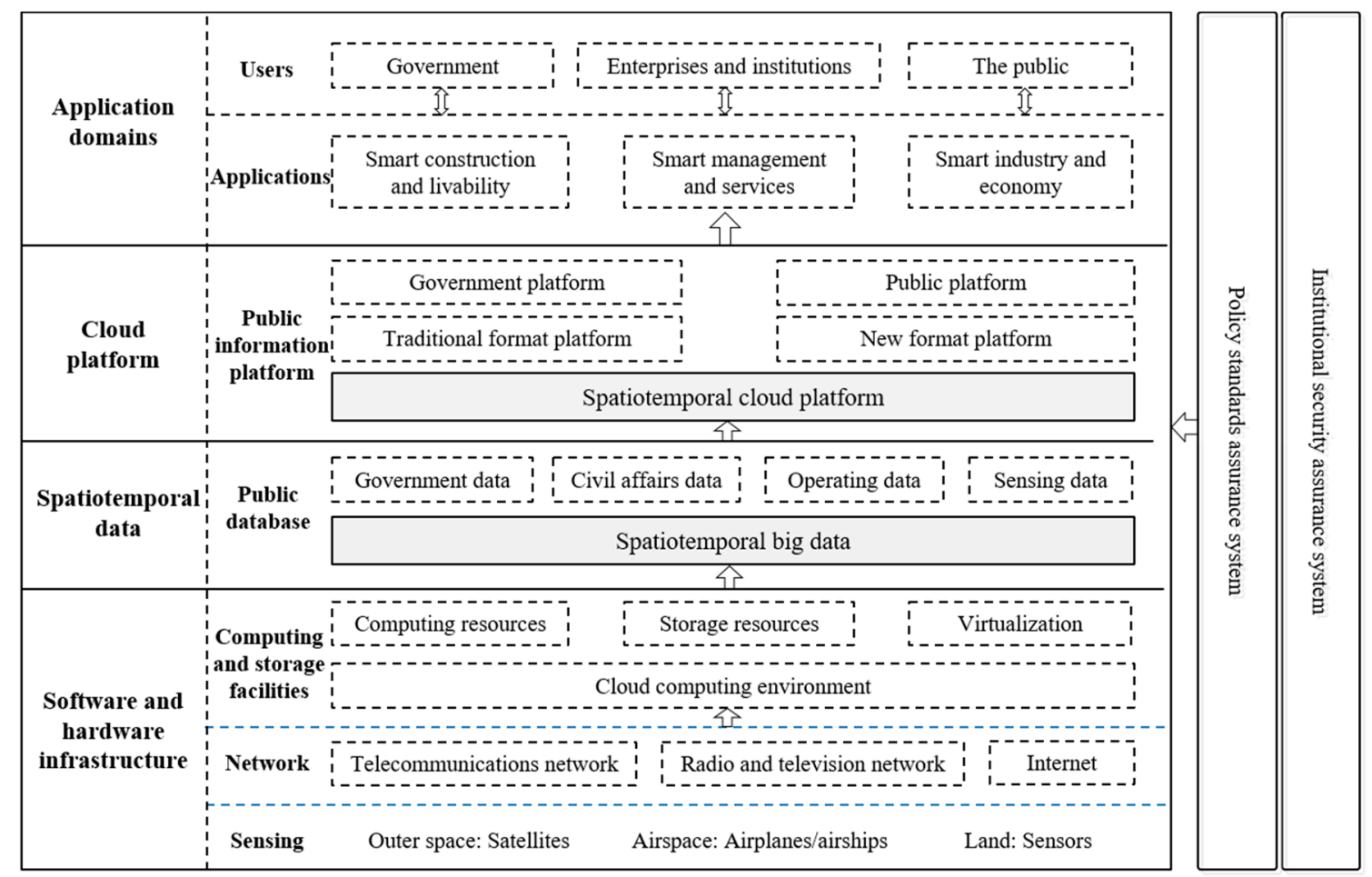

Figure 2. Smart city conceptual framework.

The sensor layer can achieve integrated data sensing of urban airspace, outer space and land, thus representing one of the key features distinguishing smart cities from urban informatized construction in the past. The network layer can achieve the transmission of various types of information and is a core infrastructure of smart city construction. Computing and storage facilities refer to cloud computing environment facilities for secure and efficient computing and the storage of acquired data and information. The above three layers are collectively called the 'software and hardware infrastructure'.

The public database is the data foundation for the unified construction of a smart city, providing a unified database and benchmark for sharing and connecting in the smart city. Government data, civil affairs data, commercial operations data and various types of intelligent sensing data are treated individually in this paper. This layer corresponds to 'spatiotemporal data'. 
The public information platform mainly transforms spatiotemporal data, infrastructure and other content into information services and resources that can be shared and exchanged. These information services and resources are publicly available to the government, the public and businesses, thus building a common platform that supports the integration and aggregation of different resources and the open sharing of services. This layer corresponds to the 'cloud platform'.

The applications layer provides applications services to the three domains of the government, the public, enterprises and institutions. To fulfill the various services provided by the public information platform, the applications layer performs service extraction and encapsulation of domain-oriented applications, providing specified common services and technical support within the domains, and fully serving the different domain applications of the smart city. By directly selecting applications in the applications layer, the user layer can directly serve multiple domains, including the government, the public and businesses as well as general, custom and other level users. This layer forms the service terminals of the entire smart city and ensures balance across different stakeholders. The two layers together form the 'application domains'.

The conceptual framework of the smart city proposed in this paper is of crucial significance to the unified construction of smart cities and the intensification of the hardware environment. More specifically, the key to ensuring the sharing and fusion of individual smart projects in the same city to achieve their unified construction lies with the construction of databases and platforms, that is, the construction of spatiotemporal data platforms in the smart city. The spatiotemporal data platform is a key component of smart city construction. It is not only an indispensable foundational information resource but also a carrier for other information sharing, exchange and collaborative applications. It provides a spatiotemporal basis for other information in the four-dimensional environment composed of three-dimensional space and time, thus realizing planning, layout, analysis and decision-making through a unified spatiotemporal environment. The spatiotemporal data and the platform will be described in Sections 3.2 and 3.3. Because the software and hardware infrastructure in the overall framework is similar to those discussed in existing studies and are relatively mature, these will not be illustrated in detail in this paper.

\subsection{Spatiotemporal Data}

Urban operating signs can be directly presented through data quantification. Many studies have shown that the collection, processing and mining of big data is an important part of smart city construction [40-43]. Allam and Dhunny (2019) proposed that data and mining analysis can help decision-makers formulate adequate and responsive policies to facilitate better urban governance [44]. Yin et al. (2015) proposed that data-centric technologies play a key role in the implementation of smart cities [16]. By summarizing studies on spatiotemporal data in smart city construction and taking into account and eliminating the data barriers between smart projects, four major areas for managing spatiotemporal big data are proposed in this paper: Resource aggregation, spatial processing, data engine and distributed management system. These four areas form a complete system from unified data acquisition, aggregation and consistency processing based on ICT and other technologies to data management and mining analysis based on artificial intelligence, thus providing a powerful guarantee for the sharing and linking of data resources and processing technologies among various smart projects. The main contents of the spatiotemporal data are shown in Figure 3.

Resource aggregation: The application of ICT in urban construction has made the acquisition of big data possible. The data in this study include basic spatiotemporal data (e.g., administrative boundary data and toponyms data), common thematic data (e.g., population data and socioeconomic data; the common thematic data is derived from information sharing among different institutes), IoT real-time sensing data (e.g., traffic monitoring video data) and Internet online crawling data (e.g., Weibo and Wechat data). These data form spatiotemporal data resources that are integrated above-below ground, indoors and outdoors, and virtually and actually. Based on these four types of data, various stakeholders can expand other thematic data needed for smart city construction based on 
their needs. The function of 'resource aggregation' aggregates a massive amount of multisource data, which can effectively resolve the issues of resource monopoly among various smart systems.

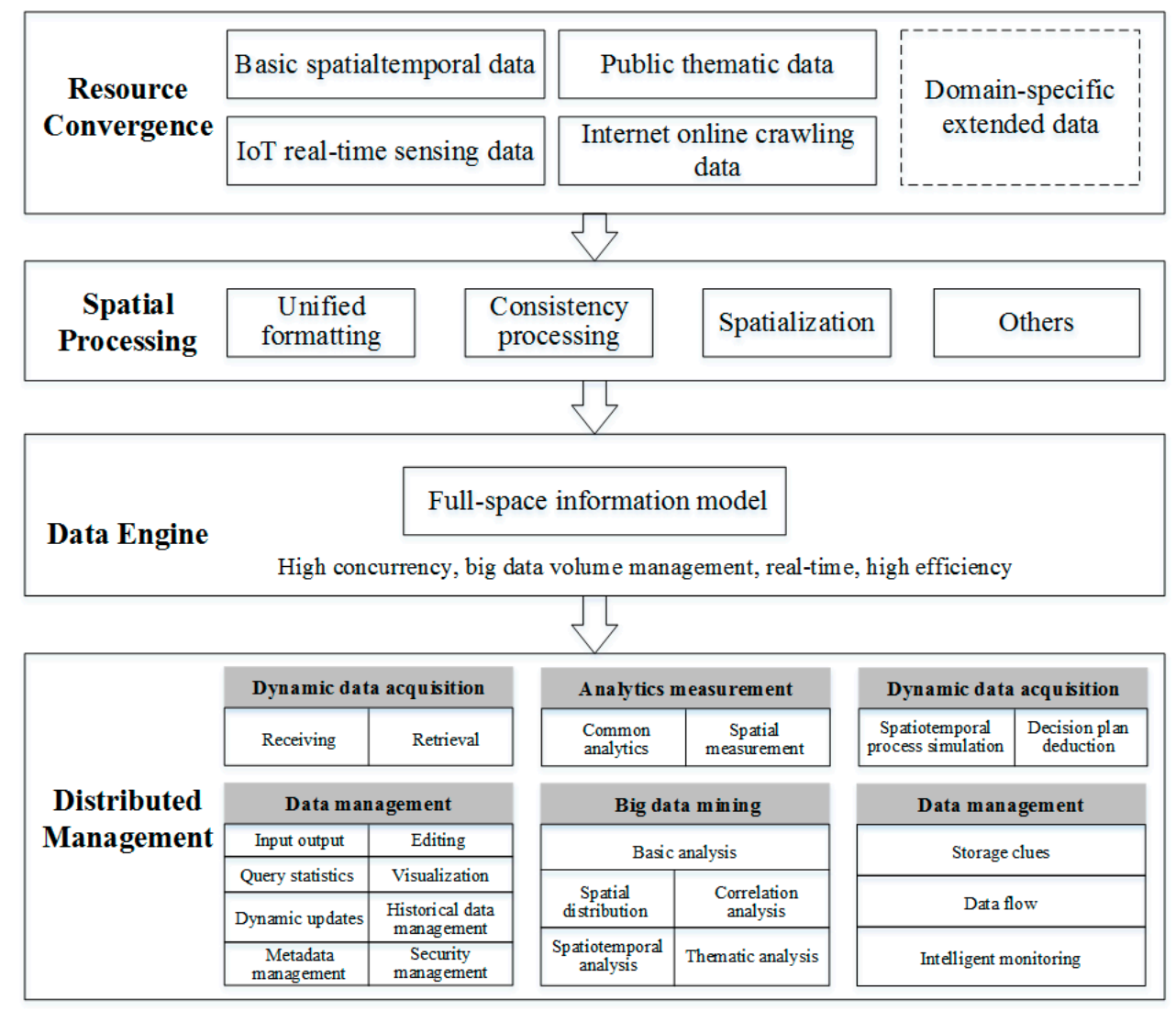

Figure 3. Contents of spatiotemporal big data framework.

Spatial processing: Big data is typically characterized by its massive characteristics, multiple sources and multi-structure [45], with widespread problems such as different measurement biases and different spatial reference information, which leads to errors in the results of subsequent analyses [46]. Therefore, before data analysis, different data need to be unified to the unified spatial reference information, formatting. More than $80 \%$ of data in the real world are related to geographic location, and it is necessary to perform spatialization processing on all data through toponym address matching and spatial reference matching. The function of 'spatial processing' can effectively resolve the issues of inconsistency in various data formats and basic data standards between smart systems.

Data engine: Through the data engine, a full-space information model can be established to achieve the integrated management of aboveground and belowground, indoor and outdoor, virtual and real, and real-time spatiotemporal data and to overcome problems of inefficient storing and accessing of spatiotemporal data. The 'data engine' helps users call off-the-shelf spatiotemporal data online.

Distributed management and analysis: It is intuitively plausible that spatiotemporal data is a series of static data stacks. However, essentially, it is a dynamic process that involves performing complex analyses on data and obtaining a series of patterns. The value of data can be captured only after it has undergone a certain degree of in-depth analysis [24,47] using neural network models, regression tree models and other models. On this basis, the prediction and deduction of the urban state are achieved through spatiotemporal process simulation and other methods to provide support for intelligent urban decision-making. The construction of this function can also provide the storage and retrieval of big data, the integration of different database types, the real-time monitoring of the operating status of each storage node and the dynamic adjustment of load balancing. 
The establishment of a management system for spatiotemporal data can effectively address the issues (1) and (2) referred to in the Introduction, that guarantee the consistency of public data and the spatial base for different smart projects in the same city, thus, it guarantees a unified data basis for the sharing and linking of different smart projects.

\subsection{Cloud Platform}

Information sharing is an important basis for achieving the integrated development of smart cities. The public information platform is a media platform for the sharing and exchange of urban information. It performs the service-oriented packaging of resources in the computing and storage facility layer and offers public data resources, development interfaces, functional models and mining knowledge, thus providing support services for the applications and user layers. Technologies such as service-oriented architecture, virtual and augmented reality, and personalized platform construction are also central to supporting the construction of this platform. In the overall framework for the smart city in this paper, the public information platform is located between the public database and the applications. It is a place where all smart city participants are able to access information and services openly, freely and conveniently, and it embodies the full sharing, fusion and mutual utilization of smart city thematic systems.

The cloud platform develops service systems and functions according to the running network and hardware environment based on the cloud center. The spatiotemporal data are intimately connected with the spatiotemporal information cloud platform, the data engine pushes the data service to the spatiotemporal information cloud platform. The composition of the cloud center is illustrated in Figure 4, and includes six parts: A service and resource pool, service engine, toponym engine, business flow engine, knowledge engine and cloud management system. With storage, data, interfaces, functions and knowledge as its core, it forms a service resource pool and establishes a service engine, toponym engine, business flow engine and knowledge engine. Together with the data engine for the spatiotemporal data, the cloud center platform provides big data support and various services according to the needs. More specifically, the service resource pool in this study mainly includes the data services provided by spatiotemporal data, application programming interface services for data processing, functional services (e.g., platform operation functions), computing and storage services and knowledge services for big data mining. The service engine is defined as a connection hub that achieving the uploading, registration and publishing of other resources. The toponym engine can implement the online spatialization of thematic data, which serves as a bridge between spatial information and other information, thereby achieving the precise positioning of big data in the full-space information model. The business flow engine mainly performs the business work using appropriate models to achieve the automatic processing of business processes. The knowledge engine implements online big data analysis, which provides big data analytics tools with different levels of capabilities to achieve the deep mining of data and acquire valuable knowledge. The cloud service system implements various functions through the visualization, modularization and servicification of different service resources and engines and provides users services while also providing managers with management and monitoring through intelligently.

The cloud platform is the medium for providing services for various users. According to the different users, three types of platforms, general platform, specialized platform and public platform, are included, which mainly reflects the service concept of 'intelligence, knowledge-oriented and convenience'.

The establishment of the cloud platform can effectively address the issues (3) and (4) referred to in the Introduction, that guarantee consistency across different smart project implementations due to different viewpoints of the project implementers or researchers, thus it guarantees balance across various stakeholders. At last, it also effectively intensifies the software and hardware environment and guarantees a unified platform and technological layer for information sharing among different smart systems. 


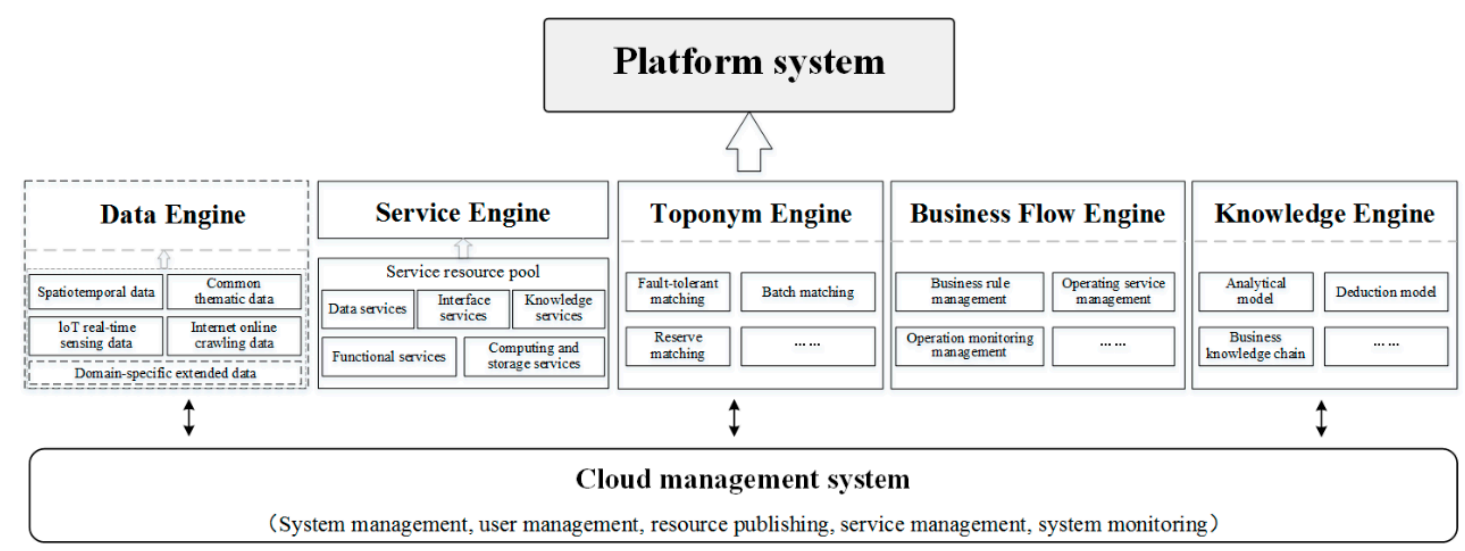

Figure 4. Cloud center.

\subsection{Application Modes for the Unified Platform}

Based on the unified spatiotemporal data cloud platform proposed in this study, it would be possible to meet the needs of different users in smart city construction and provide services to a variety of end-users. In the smart city system, the application layer and the user layer are inseparable. In the smart city application level, the focus is mainly on how to better serve the different types of users in the user layer, including the relevant government departments, enterprises and institutions, and the public. Specifically, the applications for government departments mainly involve the high fusion of information in different departments, as well as sharing and cooperation with other departments. The applications for enterprises and institutions mainly involve adding value, innovation and development. The applications for the general public are mostly concerned with how to conveniently and quickly query and discover life service needs.

The unified smart city system platform proposed in this paper is able to meet the basic application needs and rapid construction of thematic systems required by government departments, enterprises and institutions, and the public. Unlike general application systems, the system architecture proposed here is designed for different users, providing multiple types of application modes, including direct application, custom application, standard services and inline calls.

(1) Direct application: Mainly allowing ordinary users to call various service functions, load thematic information and perform spatial statistical analyses and queries.

(2) Custom application: Mainly serving custom users, who use a secondary development interface and combine it with their own special requirements to encapsulate a personalized graphical interface, but also supporting the development and expansion of functions to customize thematic application systems.

(3) Standard service: Mainly serving development users, helping them to implement map and geographic information network services, support the client in using other GIS software to develop thematic application systems and perform the distributed call of service resources.

(4) Inline call: Mainly serving embedded users by providing network linking technology to support users in performing an embedded online call of other information services without making any changes in the business operating systems that users have already put into use.

\section{Applications in Weifang City of China}

To verify the application effects of the smart city conceptual framework proposed in this paper, 334 prefecture-level smart city and 511 county-level smart city platforms were constructed from 2006 to 2017 in China, which has benefited dozens of domains, including land, planning, transportation, real estate, public security, fire protection, hygiene and public services and play an important role in socio-economic development, industry and informatization. In this section, a detailed discussion of a 
case study of smart city construction in Weifang City, Shandong Province and China is presented, which has been reported by the 'China Smarter City Development and Research Center' and a book titled "The Development Report on the New Smart Cities" [48,49]. Weifang City is the first prefecture-level city demonstration pilot with successful completion of acceptance for Smart City [50].

\subsection{General Application}

Weifang City is located in the central part of the Shandong Peninsula in China and is renowned as the kite capital of the world. Its administrative divisions include four districts, six cities and two counties covering an area of $16,100 \mathrm{~km}^{2}$ and with a total population of 9.27 million. In June 2015, Weifang City launched the "Smart City Construction Plan", which treats smart city construction as a crucial engine for accelerating socio-economic development. This plan was incorporated into the citywide top-level design and overall urban development plan, with a focus on planning compatibility, policy coordination and consistent pacing, thus providing coordinated advancement and integrated strategic leadership for smart city construction. Based on the smart city conceptual framework and platform system proposed in this paper, the construction of Smart Weifang was investigated and carried out, and a citywide cross-departmental, cross-system information resource sharing and exchange system was established (Figure 5).

The spatiotemporal data mainly includes basic geographic information data from natural resources bureau, population data from the public security bureau, and so on, which is illustrated on the left of Figure 5. By using the Weifang City resource sharing and exchange system, the data can be integrated and stored by the 'Citywide unified cloud computing center', then by using the Spatiotemporal information cloud platform, applications for public security, land and urban management, etc., can be implemented.

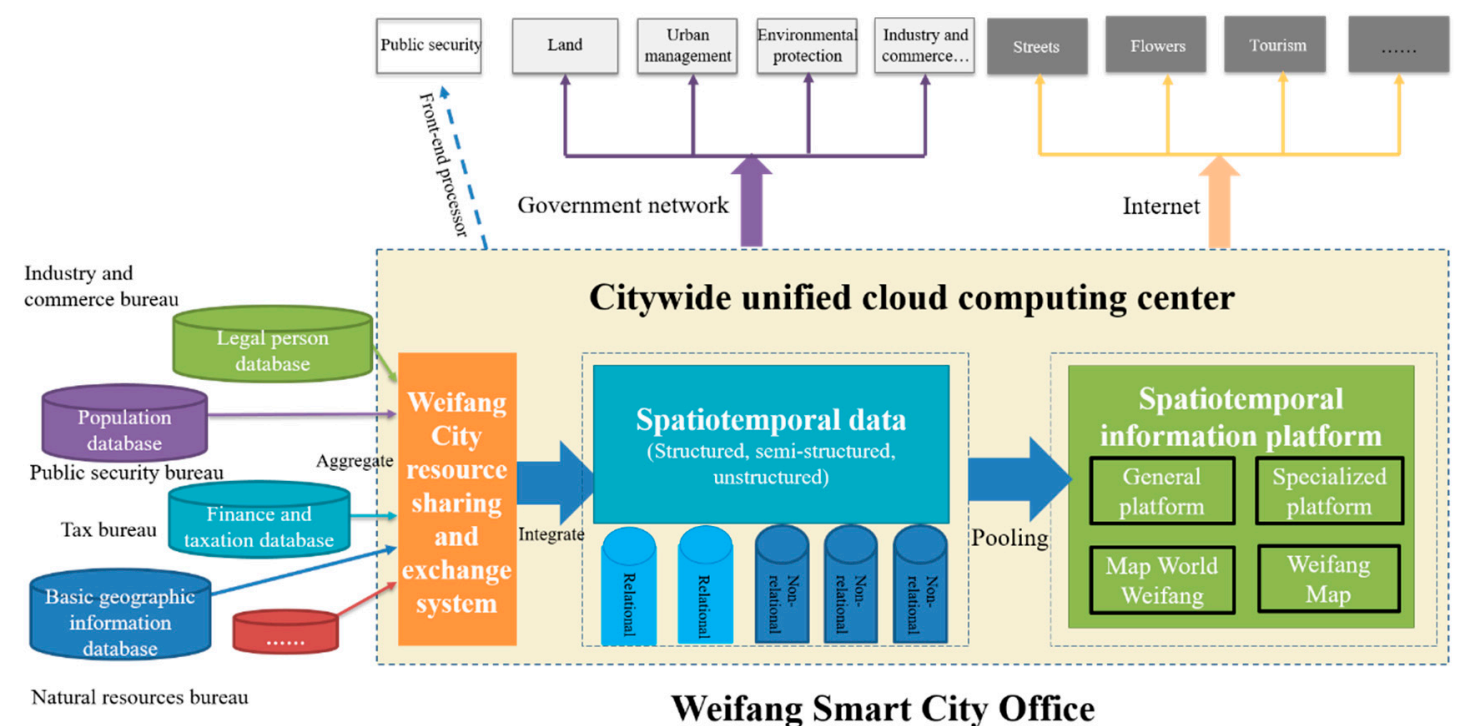

Figure 5. Smart Weifang framework.

\subsection{Construction of Spatiotemporal Data}

For resource convergence, based on the four data types proposed in this paper, different methods of data aggregation were studied and developed, such as some big data in Figure 6. Through resource aggregation, four types of big data with a volume of nearly 100 TB were ultimately aggregated. This included 10 categories of basic geographic information data amounting to $50 \mathrm{~TB}, 60$ million items of thematic data from 22 industries and 49 municipal departments in Weifang City, six categories with 129 items of spatial planning data and 10 types of real-time intelligent sensing data from more than 100,000 terminals, which altogether provided a solid and rich data foundation for the construction of 
Smart Weifang. In addition, to facilitate resource aggregation, the Weifang City sharing and exchange platform for information resources was developed and built, and a real-time processing platform for streaming data was used to capture video surveillance, air quality and other real-time data. Because these aggregated data were mostly stored in the form of relational databases, data cleaning and spatial temporalization were implemented. For the data renewal period, Smart Weifang implemented a "ten-day, monthly and quarterly updates" strategy, whereby toponymic data were updated every ten days, information on vectors, images, terrain, underground pipelines and other changes were recorded once a month, and platform-related service data were settled every quarter. This ensured the overall freshness of the basic data.

For spatial processing, due to that the collected data is mostly formed with table formation, in order to realize the mapping and matching in spatial and temporal dimension, address matching algorithm, spatialization, the discovery and identification of spatial distribution patterns, time series development patterns and attribute structural patterns for thematic data, as well as the deep mining of association relationships and causal relationships between multiple types of thematic data, were implemented. The processing data contains historical and current basic geographic information data, common thematic data and spatial planning data, real-time sensing data in Weifang City.

For data engine and distributed management, for some geographic information data, the relational database storage method is used. For data such as tables, video and pictures, the non-relational distributed database is used for storage. The client desktop management system mainly provides spatiotemporal big data desktop applications, including spatiotemporal data input and output, query, visualization, analysis, application and other functions, to achieve the integration of spatiotemporal data management. The data engine is in the middle of database and desktop management, to realize data discovery, data access, data integration and facilitate efficient data access and retrieval. In addition, the big data mining contains the distribution of the schools, the distribution of the real estate and the educational institution, the air quality and the emission of the exhaust gas, the enterprise data and the income of the fiscal and taxation, the travel characteristics of the public bicycle and the bus, and so on, which have enhanced the government's methodical and detailed decision-making, as well as its ability to carry out predictions, warnings and emergency responses.

Overall, spatiotemporal data construction in Smart Weifang, has effectively eliminated the data and resources barriers between systems, and guarantee the unified space-time reference.
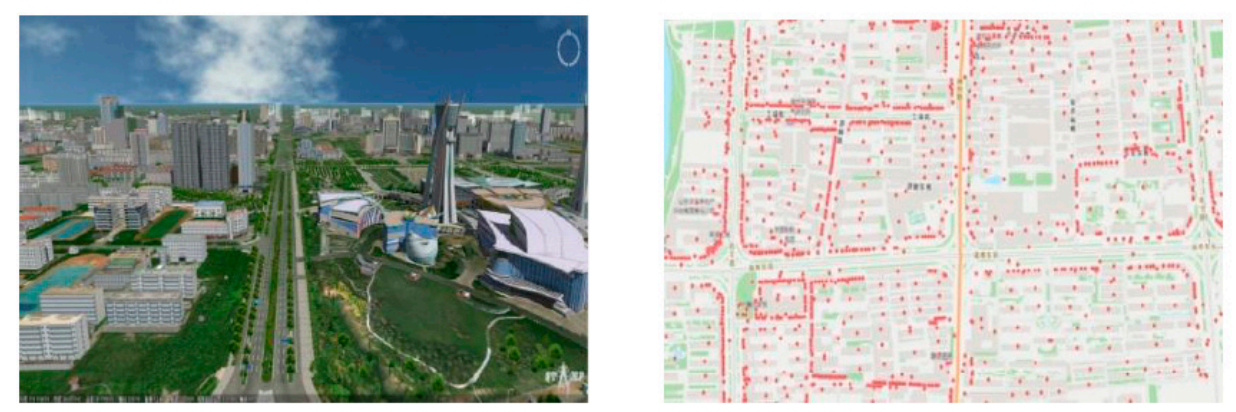

(left: fine three-dimensional model; right: toponymic data)

Figure 6. Weifang City spatiotemporal big data.

\subsection{Construction of the Cloud Platform}

As a platform medium for providing spatiotemporal information services to different types of users, Smart Weifang constructed three types of platforms according to its different application targets-the general, specialized and public platforms-which concisely embody its service philosophy of "Intelligentization, Smartification, Knowledgization". Figure 7 presents an example of Smart Weifang cloud platform. 
For general platform, it primarily implements functions based on the cloud platform architecture proposed in this paper. It mainly provides services for the integration of citywide spatiotemporal information, the autonomization of cloud platform selection autonomy and knowledgization from big data mining. In Smart Weifang, the toponym engine, business flow engine and knowledge engine of the cloud platform is constructed in the business process of the application system, such as the spatiotemporal sequencing of population, legal person, fiscal and taxation data and so on, thus, have been fully applied in the analysis and mining of big spatiotemporal data.

Based on the general module of the cloud platform, the specialized platform is oriented towards Weifang City's work demands for the integration of multiple plans and the management of natural resources. Thus, the relevant specialized data and implemented functional modules are expanded to build a specialized spatial planning platform and a specialized natural resource monitoring platform to better serve the natural resource monitoring and spatial planning work in Weifang City.

For public platforms, it includes "Map World: Weifang" on computer terminals and "Weifang Map" on mobile terminals. In addition to providing various types of data services that are available to the public, it also publishes information on real estate registrations, healthcare, police services, bike-sharing, bank branches and so on, thus truly achieving the provision of informatized services.

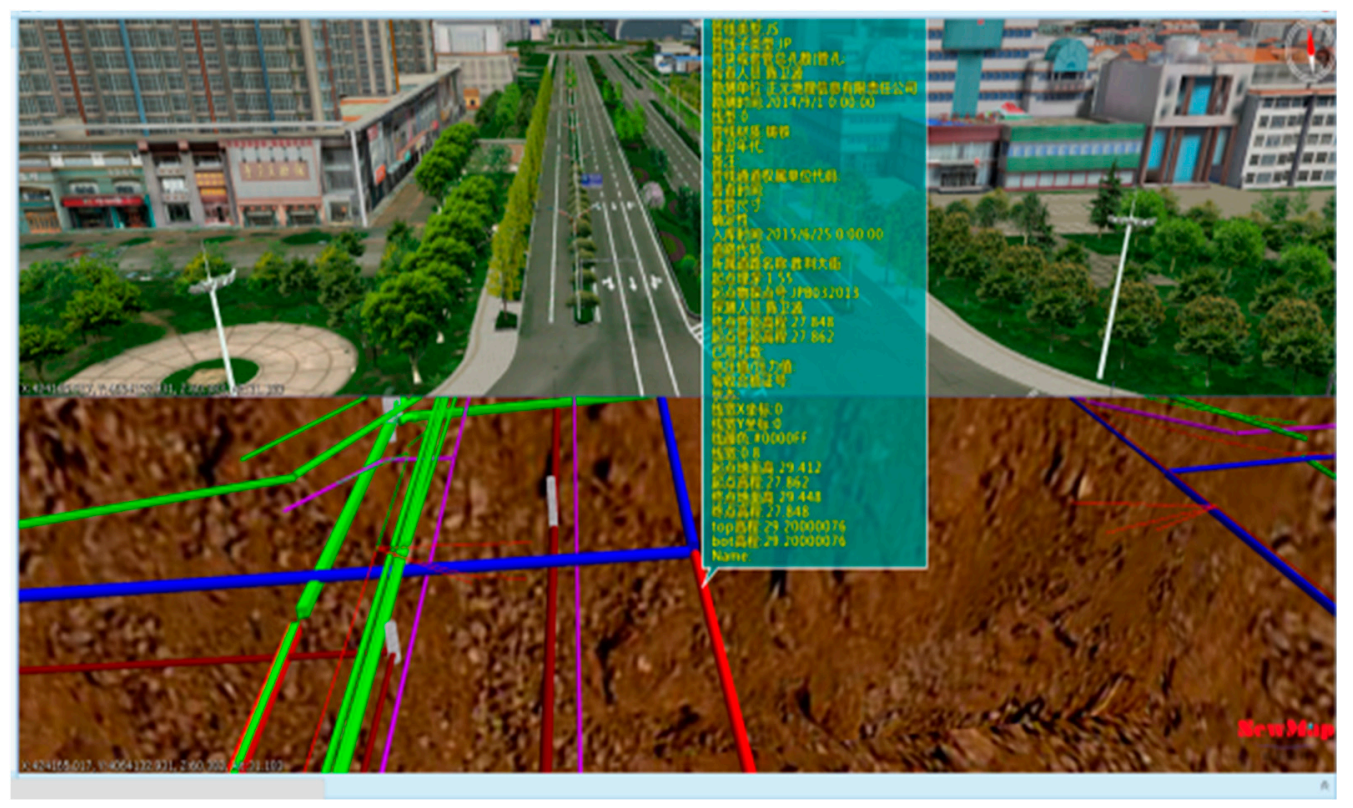

Figure 7. 3D model and underground pipeline data management in the Smart Weifang cloud platform.

By 2017, the Smart Weifang system aggregated, published and shared more than 900 service resources, nearly 300 graphic data resources and four categories of more than 20 knowledge results, as well as docking hundreds of third-party application systems. The construction of a common platform has significantly improved citywide cross-department and cross-system information sharing, thereby forming the coordinated advancement and integrated strategic leadership of Smart Weifang.

\subsection{Evaluation of Application Effects}

The construction of Smart Weifang effectively integrates resource data that were scattered across various departments and establishes a citywide, cross-departmental, cross-system information resource sharing and exchange system based on a unified spatial foundation. It has greatly improved the level of public services and achieved accurate and intelligent urban operations management. Currently, this system has been applied in more than 30 systems across more than 20 departments and domains in Weifang City. 
In terms of information sharing, the construction of Smart Weifang has effectively eliminated the data and technological barriers between systems. Moreover, the construction of a common platform has significantly improved citywide cross-department and cross-system information sharing, thereby forming the coordinated advancement and integrated strategic leadership of smart city construction.

In terms of socio-economic benefits, the construction of Smart Weifang has effectively prevented redundant financial investments, thus providing major cost savings and producing good economic benefits (approximately RMB 200 million per year) [50]. More specifically, compared to the duplicate data purchases originally made by individual departments, the costs of large-scale topographic maps, electronic maps, 3D models and other data covering only $351 \mathrm{~km}^{2}$ of the Weifang City metropolitan area and $640 \mathrm{~km}^{2}$ of the eight counties and cities resulted in annual savings of RMB 150 million. In terms of software and hardware infrastructure, this common platform allowed the different departments to store large amounts of shared data in the cloud center. Compared to the case in which each department purchases individual software and hardware equipment for separate storage, this platform has effectively achieved hardware intensification and multiple usage, thus avoiding redundant financial investments and saving approximately RMB 18 million per year. For the development of thematic services, traditional smart city platform construction, from data generation to procurement of basic software and hardware to system development, tends to have a research and development cycle of more than half a year, generally requiring 1-2 years. However, by adopting this access platform to directly perform secondary development and thematic domain application, the cycle can be shortened by 6-8 months. Hence, it not only improves efficiency but also reduces development costs by approximately RMB 15 million per year.

Based on a comparison with the indicators of original smart project construction, the shareable smart city framework proposed in this paper was highly innovative, strongly systemic and had significant socio-economic benefits. It can provide a scientific basis to support scientific urban decision-making, rational planning, careful management and efficient operations. Professor Qin Qiming of Peking University, who is an expert in the field of geographic information, believes that the complete set of technologies and construction models developed in Smart Weifang has provided a solution to the construction of smart cities in China that can be replicated, promoted and implemented. In 2017, Smart Weifang passed inspection by China's former State Bureau of Surveying and Mapping and became the first pilot prefecture-level city to pass this inspection.

\section{Conclusions}

By analyzing the framework connotations and application domains of the smart city, this paper proposed a common, shareable and integrated conceptual framework for smart cities. Then, based on this framework, a unified portal platform that is suitable for multiple domains, including the government, citizens and businesses allowing common, custom and other application modes is proposed. Finally, Smart Weifang was implemented based on this platform. The application outcomes indicate that this common and shareable platform can effectively eliminate the data and technological barriers between different smart city systems while also avoiding redundant financial investments. The investigation of the proposed framework and platform is of key significance to the unified construction of smart cities and the intensification of the hardware environment, thus representing a true achievement in the transition from 'information islands' to 'information sharing and interconnection' for urban informatization.

The smart city is a new concept that uses ICT to promote the smartification of urban construction, planning and services. Currently, a number of countries and cities have conducted studies on smart cities, but they mostly focus on analyzing the conceptual connotations or applications in specific domains. There is a lack of studies on common, shareable and integrated systems, which has led to significant barriers between various smart systems. To address these issues, this paper performed an in-depth analysis of the connotations and applications of smart city frameworks and proposed a common, shareable and integrated conceptual framework for a smart city. Based on this framework, a unified portal that is suitable for multiple domains, including the government, citizens and businesses 
as well as general, custom and other application modes, was proposed. This study has important implications for the unified construction of smart cities, the intensification of hardware environments and the real-world achievement of integrated smart city construction. It can provide theoretical support for the unified construction and application of smart cities. The main conclusions of this study are as follows:

(1) Based on an in-depth analysis of the connotation of smart cities, four key aspects-software and hardware infrastructure, spatiotemporal big data and processing, cloud platform system and application domains-are proposed and understood for the smart city.

(2) A common, shareable and integrated framework was proposed for Smart City. There are four main structures in this framework: The software and hardware infrastructure layer, the public database layer, the cloud platform layer, the smart applications layer and the user layer.

(3) The study summarized the key technologies for smart city construction, centered on spatiotemporal big data and cloud platforms, which will guarantee that information sharing among individual systems in smart cities will be unified at the data and technological levels.

(4) Based on the proposed shareable framework and platform, Smart Weifang was constructed. The application effects indicated that it can effectively eliminate the data and technological barriers between systems, which significantly improved citywide cross-department and cross-system information sharing, thereby providing the coordinated advancement and integrated strategic leadership of smart city construction. In terms of socio-economic benefits, it effectively prevented redundant financial investments and offered substantial cost savings. According to incomplete statistics, when compared to traditional smart city construction, Smart Weifang saved approximately RMB 150 million a year in expenses, hence providing good economic benefits.

This paper investigated and designed a common framework and platform system for smart cities from the perspective of information sharing and integration. We have also described the framework architecture and certain key technologies. However, the specific implementation technologies and models were not discussed directly in the article. With the emergence of different structural data, the real-time updating of new processing techniques and methods will become especially crucial for the common platform. Additionally, from the data aspect, when the data provided by governments or other institutes are all text-structured without unique coding or spatial information, or they do not provide authoritative basic information, which will both lead to incomplete construction of the spatiotemporal database. Therefore, in future research, more emphasis will be placed on the improvement of the framework, design of intelligent technologies, upgrading of the platform system to ensure the provision of long-term and effective support for the application and development of big data in smart cities.

Author Contributions: C.L. conceived the original idea for the study, and all co-authors conceived and designed the methodology. X.L., Z.D. and Z.Z. conducted the processing and analysis of the data. C.L., X.L. and Z.D. drafted the manuscript. All authors read and approved the final manuscript.

Funding: This research was funded by the National Natural Science Foundation of China (41871375), National Key Research and Development Program of China (2018YFB2100700), Basic scientific research of Chinese Academy of Surveying and Mapping (AR1909, AR1916).

Conflicts of Interest: The authors declare no conflicts of interest.

\section{References}

1. Dirks, S.; Keeling, M. A Vision of Smarter Cities: How Cities Can Lead the Way into a Prosperous and Sustainable Future; IBM Institute for Business Value: Somers, NY, USA, 2009.

2. United Nations, Department of Economic and Social Affairs. World Urbanization Prospects: The 2014 Revision; United Nations, Department of Economic and Social Affairs: New York, NY, USA, 2014.

3. Victoria, F.A.; José, M.F.-G.; Rudolf, G. Smart City implementation and discourses: An integrated conceptual model. The case of Vienna. Cities 2018, 78, 4-16. 
4. Alawadhi, S.; Aldama-Nalda, A.; Chourabi, H.; Gil-Garcia, R.J.; Leung, S.; Mellouli, S.; Nam, T.; Pardo, T.A.; Scholl, H.J.; Walker, S. Building understanding of Smart City initiatives. In International Conference on Electronic Government; Lecture Notes in Computer Science; Springer: Berlin/Heidelberg, Germany, 2012; Volume 7443, pp. 40-53.

5. Chourabi, H.; Nam, T.; Walker, S.; Gil-Garcia, R.J.; Mellouli, S.; Nahon, K.; Pardo, T.A.; Scholl, H.J. Understanding smart cities: An integrative framework. In Proceedings of the 2012 45th Hawaii International Conference on System Sciences, Maui, HI, USA, 4-7 January 2012; pp. 2289-2297.

6. Palmisano, S.J. A Smarter Planet: The Next Leadership Agenda; IBM: Armonk, NY, USA, 2008.

7. Harrison, C.; Eckman, B.; Hamilton, R.; Hartswick, P.; Kalagnanam, J.; Paraszczak, J.; Williams, P. Foundations for smarter cities. IBM J. Res. Dev. 2010, 54, 1-16. [CrossRef]

8. Giffinger, R.; Gudrun, H. Smart cities ranking: An effective instrument for the positioning of the cities? Archit. City Environ. 2010, 4, 7-26.

9. Belissent, J. Getting Clever about Smart Cities: New Opportunities Require New Business Models; Forrester: Cambridge, MA, USA, 2010.

10. Mitton, N.; Papavassiliou, S.; Puliafito, A.; Trivedi, K.S. Combining Cloud and sensors in a smart city environment. EURASIP J. Wirel. Commun. Netw. 2012, 247. [CrossRef]

11. Peris-Ortiz, M.; Bennett, D.R.; Yábar, D.P.B. Sustainable Smart Cities: Creating Spaces for Technological, Social and Business Development; Springer: Berlin, Germany, 2016; ISBN 9783319408958.

12. Su, K.; Li, J.; Fu, H. Smart city and the applications. In Proceedings of the IEEE International Conference on Electronics, Communications and Control (ICECC), Ningbo, China, 9-11 September 2011; pp. 1028-1031.

13. Javidroozi, V.; Shah, H.; Amini, A.; Cole, A. Smart city as an integrated enterprise: A business process centric framework addressing challenges in systems integration. In Proceedings of the 3rd International Conference on Smart Systems, Devices and Technologies, Paris, France, 20-24 July 2014; pp. 55-59.

14. BSI (British Standards Institution). PAS 181:2014: Smart City Framework—Guide to Establishing Strategies for Smart Cities and Communities; BSI Standards Limited; BSI Standards Publication: London, UK, 2014.

15. ISO (International Standards Organization). 37106 Sustainable cities and communities_Guidance on Establishing Smart City Operating Models for Sustainable Communities; Sustainable Cities and Communities; International Standards Organization: Geneva, Switzerland, 2018.

16. Yin, C.T.; Xiong, Z.; Chen, H.; Wang, J.Y.; Cooper, D.; David, B. A literature survey on smart cities. Sci. China Inf. Sci. 2015, 58, 1-18. [CrossRef]

17. Lombardi, P.; Giordano, S.; Caragliu, A.; Del Bo, C.; Deakin, M.; Nijkamp, P.; Kourtit, K. An advanced triple-helix network model for smart cities performance. In Green and Ecological Technologies for Urban Planning: Creating Smart Cities; Ozge, Y., Hershey, P.A., Eds.; IGI Global: Hershey, PA, USA, 2012; Volume 59, p. 73.

18. Deakin, M. Smart cities: The state-of-the-art and governance challenge. Triple Helix 2014, 1, 7. [CrossRef]

19. Hall, R.E. The vision of a smart city. In Proceedings of the 2nd International Life Extension Technology Workshop, Paris, France, 28 September 2000.

20. Schaffers, H.; Komninos, N.; Pallot, M.; Trousse, B.; Nilsson, M.; Oliveira, A. Smart cities and the future Internet: Towards cooperation frameworks for Innovation. Future Internet 2011, 6656, 431-446.

21. Batty, M. Big data, smart cities and city planning. Dialogues Hum. Geogr. 2013, 3, 274-279. [CrossRef]

22. Lim, C.; Kim, K.-J.; Maglio, P. Smart cities with big data: Reference models, challenges, and considerations. Cities 2018, 82, 86-99. [CrossRef]

23. Hashem, I.A.T.; Chang, V.; Anuar, N.B.; Adewole, K.; Yaqoob, I.; Gani, A.; Ahmed, E.; Chiroma, H. The role of big data in smart city. Int. J. Inf. Manag. 2016, 36, 748-758. [CrossRef]

24. Nuaiim, E.A.; Neyadi, H.A.; Mohamed, N.; Al-Jaroodi, J. Applications of big data to smart cities. J. Internet Serv. Appl. 2015, 6, 25. [CrossRef]

25. Nam, T.; Pardo, T.A. Conceptualizing smart city with dimensions of technology, people, and institutions. In Proceedings of the 12th Annual International Digital Government Research Conference: Digital Government Innovation in Challenging Times, College Park, MD, USA, 12-15 June 2011; pp. 282-291.

26. Li, C.M. What is a smart city? Land Resour. Her. 2014, 9, 49-50.

27. Li, D.R.; Shao, Z.; Yang, X. Theory and Practice from Digital City to Smart City. Geospat. Inf. 2011, 9, 1-5. 
28. Cheng, B.; Longo, S.; Cirillo, F.; Bauer, M.; Kovacs, E. Building a Big Data Platform for Smart Cities: Experience and Lessons from Santander. In Proceedings of the 2015 IEEE International Congress on Big Data, New York, NY, USA, 29 October-1 November 2015; pp. 592-599.

29. Lazaroiu, G.C.; Roscia, M. Definition methodology for the smart cities model. Energy 2012, 47, $326-332$. [CrossRef]

30. European Smart Cities. Centre of Regional Science Vienna University of Technology. 2012. Available online: http://www.smart-cities.eu/model.html (accessed on 5 September 2012).

31. Catarinucci, L.; Donno, D.; Mainetti, L.; Palano, L.; Patrono, L.; Stefanizzi, M.L.; Tarricone, L. An IoT-Aware Architecture for Smart Healthcare Systems. IEEE Internet Things J. 2015, 2, 515-526. [CrossRef]

32. Baig, M.M.; Gholamhosseini, H. Smart Health Monitoring Systems: An Overview of Design and Modeling. J. Med. Syst. 2013, 37, 9898. [CrossRef]

33. Debnath, A.K.; Chin, H.C.; Haque, M.M.; Yuen, B. A methodological framework for benchmarking smart transport cities. Cities 2014, 37, 47-56. [CrossRef]

34. Ding, Z.M.; Yang, B.; Chi, Y.Y.; Guo, L. Enabling Smart Transportation Systems: A Parallel Spatio-Temporal Database Approach. IEEE Trans. Comput. 2016, 65, 1377-1391. [CrossRef]

35. Benevolo, C.; Dameri, R.P.; D'Auria, B. Smart mobility in smart city. In Empowering Organizations: Enabling Platforms and Artifacts; Springer: Heidelberg, Germany, 2015; Chapter 2; pp. 13-28.

36. Buhalis, D.; Amaranggana, A. Smart Tourism Destinations. In Information and Communication Technologies in Tourism; Springer: Cham, Switzerland, 2014; Chapter 40; pp. 553-564.

37. Li, Y.P.; Hu, C.; Huang, C.; Duan, L. The concept of smart tourism in the context of tourism information services. Tour. Manag. 2017, 58, 293-300. [CrossRef]

38. Maalsen, S. Smart housing: The political and market responses of the intersections between housing, new sharing economies and smart cities. Cities 2019, 84, 1-7. [CrossRef]

39. Petrolo, R.; Loscrì, V.; Mitton, N. Towards a smart city based on cloud of things, a survey on the smart city vision and paradigms. Trans. Emerg. Telecommun. Technol. 2015, 28, e2931. [CrossRef]

40. Kitchin, R. The real-time city? Big data and smart urbanism. GeoJournal 2014, 79, 1-14. [CrossRef]

41. Mehmood, R.; Meriton, R.; Graham, G.; Hennelly, P.; Kumar, M. Exploring the influence of big data on city transport operations: A Markovian approach. Int. J. Oper. Prod. Manag. 2017, 37, 75-104. [CrossRef]

42. Souza, A.; Figueredo, M.; Cacho, N.; Araújo, D.; Prolo, C.A. Using big data and real-time analytics to support smart city initiatives. IFAC-PapersOnline 2016, 49, 257-263. [CrossRef]

43. Zhang, D.; Song, T.; Li, J.; Liu, Q. A linked data-based framework for personalized services information retrieval in smart city. In Proceedings of the Workshops on Web Information Systems Engineering, Nanjing, China, 13-15 October 2013; Springer: Berlin/Heidelberg, Germany, 2014; pp. 461-473.

44. Allama, Z.; Dhunny, Z.A. On big data, artificial intelligence and smart cities. Cities 2019, 89, 80-91. [CrossRef]

45. Chen, M.; Mao, S.; Liu, Y. Big data: A survey. Mobile Netw. Appl. 2014, 19, 171-209. [CrossRef]

46. Fan, J.; Han, F.; Liu, H. Challenges of big data analysis. Natl. Sci. Rev. 2014, 1, 293-314. [CrossRef]

47. Al Nuaimi, E.; Al Neyadi, H.; Mohamed, N.J. Applications of big data to smart cities. J. Internet Ser. Appl. 2015, 6, 1-15. [CrossRef]

48. China Smarter City Development and Research Center. The Publication of 'The Development Report on the New Smart Cities, 2017' in Beijing. Available online: http://scdrc.sic.gov.cn/news/339/8708.htm (accessed on 27 December 2017).

49. Lin, N.; Zhuang, R.; Ren, Z.; Qin, H.; Cheng, X.; Wu, H.; Shan, Z.; Liu, Y. The Development Report on the New Smart Cities; China Planning Press: Beijing, China, 2017.

50. Taibo. Smart Weifang Spatiotemporal Database and Cloud Platform Construction through the National Acceptance and Be Evaluated as International Advanced Standards. Available online: http://www.3snews. net/column/252000048874.html (accessed on 6 November 2017).

(C) 2019 by the authors. Licensee MDPI, Basel, Switzerland. This article is an open access article distributed under the terms and conditions of the Creative Commons Attribution (CC BY) license (http://creativecommons.org/licenses/by/4.0/). 